\title{
The Breadth of Success and Failure Factors with PPPs Implementation
}

\author{
Ncedo Cameron Xhala - Juraj Nemec- \\ Kahilu Kajimo-Shakantu*
}

\begin{abstract}
:
The financing of public infrastructure investment through public-private partnerships faces daunting challenges related to the success of implementation of public infrastructure investment. There are multi-dimensional competing factors which inhibit the short and long-term implementation of PPPs, some of them may result to failure of implementation. The implementation of PPPs requires a set of success factors and its positive result is not automatic. This paper offers an overview of challlenges facing the implementation of PPPs and lists the most important success factors which increase the chance for successful implementation of PPPs. This paper further explores the range and ranking of the most important successful factors required for the realization of PPPs.
\end{abstract}

Key words: Public Infrastructure; Investment; Public-Private Partnerships.

JEL classification: H89.

\section{Introduction}

The search for the alternative financing of public infrastructure investment intrigues public and private participation implementation as an alternative financing instrument. The search for new financing instruments is championed by the earliest suboptimal expenditures on public infrastructure investment which reflected substantial inadequacies in the financing of infrastructure investment (Della-Crose and Gatti, 2014).

However, public private partnerships projects are not single dimensional issue. Roseneau (1999) highlights that the success or failure of PPPs projects has not been systematically appraised. Consequently, the debate on PPPs still focuses on "public bad and private good" with selective evidence championing this debate

Ncedo Cameron Xhala; Masaryk University, Faculty of Economics and Administration, Department of Public Economics, Lipova 41a, 60200 Brno, Czech Republic, <cameron.xhala@gmail.com>.

Juraj Nemec; Masaryk University, Faculty of Economics and Administration, Department of Public Economics, Lipova 41a, 60200 Brno, Czech Republic, <juraj.nemec@econ.muni.cz>.

Kahilu Kajimo-Shakantu; University of the Free State, Faculty of Natural and Agricultural Sciences, Department of Quantity Survey and Construction Management, 205 Nelson Mandela Drive Park West, 9300 Bloemfontein, South Africa, <KajimoShakantu@ufs.ac.za>.

The article is processed as an output of the research project Performance Management in Public Administration: Theory and Practice in the Czech Republic and other CEE Countries project registered by the Czech Grant Agency under the registration number GA16-13119S. 
about the "private good" and "public bad" (Spackman, 2002; Broadbent and Laughlin, 2003).

Della-Crose and Gatti (2014) also suggest that the plausible financing shift of public infrastructure investment from the public sector to the private sector pose significant challenges to success implementation of PPPs. This paper acknowledges the theoretical consideration of success and failure factors with implementation of infrastructure investment projects and proposes the most important success and failure factors of PPPs infrastructure investment projects.

The authors of this paper acknowledge substantial growth and support for implementation of PPP infrastructure investment project across the developed and the developing countries. Although, there is strong support for PPP infrastructure investment implementation a number of delineated challenges for PPPs infrastructure investment projects results to failure of projects. This paper offers an overview of the most important success factors which impact successful implementation of PPPs infrastructure investment projects. The paper is organized as follows; Section 2 provides an overview of literature review on failure and success of PPP projects, Section 3 proposes the most important success factors that contributes to success implemntation of PPPs. Section 4 provides the methodology and findings of the field research, and Section 5 is the conclusion.

\section{Experiences with PPPs (with focus on the Czech Republic and Slovakia situation)}

Ngowi, Pienaar, Akindele, and Iwisi (2006) elucidate that the challenges confronting the financing of public infrastructure investment is of global concern as they contribute to the increased infrastructural deficit which lately has become a norm to both the developing and developed countries. Soni (2015) explains that the requirements for infrastructure investment in the 20th century require substantial capital upfront for basic and critical infrastructure. The implementation of public infrastructure investment requires substantial shifts from being tools for political fielding as instruments of re-election into political office, rather than the consideration of financing risks, infrastructure feasibility and the value for money that is grounded on financial sustainable of infrastructure development. The collaborative expectancy of both implementing partners within a partnership through PPPs requires a profound commitment, readiness and preparedness of both partners. Not just the allocation of risks should become the norm, but a considerate approach into focused justification of infrastructure project's financial and feasible viability. The appropriateness of implementing the infrastructure projects shall be evaluated, instead of the "pleasant" political consideration of infrastructure investment. 
An analysis of a number of failed PPP infrastructure investment projects (for example Soni, 2015) highlights a number of failure factors which contributed to the collapse of PPP infrastructure investment projects. The substantial amount of factors which led to failure of PPP projects resulted to incomplete or stalled, or the total failure of PPP infrastructure investment projects signaling the official status of failure into PPP projects. Soni (2015) also highlights further that as a result of infrastructure project failure, economic performance is immensely affected due to lack of sustained increased growth rates.

Aayog (2015) claims further that the overwhelming factor of failure of PPP infrastructure investment projects is increased unaccounted transactional costs. For instance, the transactional costs experienced in India comprised of prolonged dispute resolution and land acquisition.

Furthermore, Pavel in a personal interview explained that the two factors which also contributes to failure of PPP infrastructure investment projects, as reflected in the case of Czech Republic, comprised of prolonged or lack of Environmental Authorization and the failure of land acquisition before the implementation of the infrastructure project. These factors adversely affect the success implementation of PPP infrastructure investment projects.

Soni (2015) describes other contributing factors with adverse effects to implementation of PPP infrastructure investment projects. According to him the lack of capacity to systematically assess the risks and the efficient allocation of risks is core factor of failure with negative effects to the success implementation of PPP projects.

Witz in a personal interview explained that the significance of risk allocation comprised an "optimal allocation of risks between the partners", and the "public partner is required to make strategic decisions with objectives of implementing the PPP infrastructure project". In addition, Witz highlighted that the "risk shall be borne by the partner that is best positioned to bear the risks". This indicates that both partners within the PPPs shall consider the whole range of risks connected with every PPP infrastructure investment project. However, this practice is lacking because the public sector tends to transfer all the risks to the private partner resulting to the total failure of infrastructure investment projects. The public sector in the PPP partnership should also keep some risks which it can manage to safeguard the total failure of the project through the total transfer of all risks to the private partner. The significant failure to consider these range of risks contributes to the failure of PPP infrastructure investment projects, risks allocation being the main factor reported to the total failure of projects.

In case of the PPP infrastructure projects with reported failure results, authors report significant misunderstanding of what PPPs are, contributing to the unrealistic expectations which contributed to conflicting mismatch of policy and 
the development of financial instrument resulting to failure of PPPs (Dheret, Martens, Zuleeg, 2012).

The challenge in Slovakia with PPPs which resulted to failure of infrastructure investment project implementation comprised the issues PPP contracting which resulted to overpricing of PPP infrastructure investment implementation as well as lack of private sector competition (Kovalcik, 2010). This suggest that the main factors attributed for the failure of PPPs in Slovakia comprised the lack of costs benefit analysis, consideration of value for money, affordability and the negotiation of PPP contracts (Kovalcik, 2015). In addition, Kubina (2015) explains that the most failure factors for the failure of PPPs in Slovakia are connected with lacking political support for the implementation of PPPs.

Pavel in the interview also highlighted the significance of methodological support that is directed towards the success implementation of PPP infrastructure investment projects as critically necessary, as most of the failed PPP infrastructure investment projects undertaken by the Czech Republic lacked methodological support. Furthermore, Ondracka (2007) adds that the factors which contributed to failure of PPPs in the Czech Republic contained of suboptimal quality of institutional capacity which resulted to lack of negotiations, lack of risk allocation and sharing, inadequate contracting management and the suboptimal governance of large infrastructural projects through the PPP scheme.

In addition, Pavel and Witz during interviews indicated that the failure factors with PPP implementation emanates from public sector's lack of capacity and the lack of readiness of as a result of lacking requisite skills in PPP implementation. Witz explained that public servants require to have basic procurement knowledge because PPP procurement is complex and such the procuring process for the implementation of PPPs require specialized technical skills as PPPs remain complex and needs a set of skills in contracting, management, monitoring and administration of contracts since PPPs is a long term contracting exercise. The adverse factors with implementation of PPPs in both the Czech and the Slovak Republic translated to the closure of one PPP infrastructure investment project in the Slovak Republic and to two closed PPP projects in the Czech Republic signaling the extent of challenges as factors which contributed to failure of PPP implementation.

Various studies identified various success factors with implementation of PPP infrastructure investment projects in various countries. Jefferies et al (2002), identified 15 success factors important to the implementation of PPP infrastructure investment projects which comprised of "complimentary skills among the key parties", "developed legal/economic framework", "political stability and the selection of the right project", feasibility study", and "good resource management" as amongst those factors considered as important to the success of PPP 
implementation. The study by Jamali (2004) found "trust, openness, and fairness as the foundational factors which contributes to the success of PPPs.

The study by Dewatripont and Legros (2005) indicates that the alleged strength of PPPs in delivering infrastructure projects on budget more often than traditional public procurement could be illusory. This is - to put it simply - because there are costs of avoiding cost overruns and, indeed, cost overruns can be viewed as equilibrium phenomena. Second, the use of external (i.e., third-party) finance in PPPs, while bringing discipline to project appraisal and implementation, implies that part of the return on efforts exerted by the private-sector partner accrues to outside investors; this may undo whatever beneficial effects arise from 'bundling' the construction and operation of infrastructure projects, which is a hallmark of PPPs.

\subsection{PPPs in the Czech Republic and Slovakia}

The expansion of PPPs in the Czech Republic is very much connected with a sharp decline of public infrastructure investment financed from the state budget resources (Kamenickova, 2012). Subsequent to the Czech consideration of PPPs in various sectors, Ondracka (2007) reports that the Czech government prepared ten pilot PPP projects in 2007 targeting the development of PPPs market in the transportation sector. World Bank (2015, https://pppknowledgelab.org) data argue that in the Czech Republic following number of PPPs was concluded:

- Water and sewage: 17

- Electricity: 17

- Natural gas: 10

- Railways: 4

- Airports: 3

- Telecoms: 15

The results from PPPs in the Czech Republic are contradictory. The study conducted by the Transparency International Czech Republic discovered that the "Czech contracting authority was not well prepared to successful implement the PPP projects because of inadequate understanding of PPPs which was viewed as easy money to solve the lack of funding" (Ondracka, 2007:9). Consequently, the D-47 PPP motorway project constitutes this misunderstanding about PPPs resulting to its total collapse. Hrncir (2009:71) describes the D-47 PPP infrastructure investment project as the first PPP project undertaken by the Czech as a motorway infrastructure class with the partnering company from Israel. Ondracka (2007) claims the value of the D-47 PPP project constituting the construction of the highway or the E-toll system amounted to CZK 35 billion a share of $1.1 \%$ of GDP. Aseidu (2004) claims that the immediate failure of the D47 project resulted to diverging attitudes with the implementation of PPP project 
as was instituted in a programmed and systematic approach. Ondracka (2007) claims that the failure resulted to development of PPP Centrum with the Ministry of Finance as a special agency mandated to implement PPP projects. The initial legislative reforms followed the failure of the D-47 project to enhance reforms with clear purpose and functions of PPPs. Aseidu (2004) highlights further that the objective focus of reforms targeted the PPP methodological approach in the area of procurement, concessions and legal aspects with the implementation PPPs in Czech Republic.

In Slovakia the situation is almost identical. The current state of affairs with fiscal tight rules and struggling public finances in Slovakia resulted to increased consideration of private sector contribution with PPPs remaining the alternative financing option for public investment (PPPs exist in Slovakia from the beginning of this century, but as small scale local projects, here we deal with major public investment projects). PPPs became visible in the time of considerating the construction of the motorway, multi-functional hall, new football stadium, reconstruction of railway station with an average volume of 6.5 billion SKK. Subsequently Slovakia started with the transportation sector that built an infrastructure featuring the $130 \mathrm{~km}$ stretch of highway connecting Western and Central Slovakia, earmarked for 2014. Kovalcik (2010) indicates that Slovakia managed the closure of only one large PPP project, however this project was significantly overpriced. Recently a lot of discussion was connected with the planned PPP project on the construction of the University Hospital in Bratislava, which did not start, yet.

\section{Methodology}

This study uses qualitative approach with semi-structured interviews as the method used for data collection. The process of data collection was qualitative in nature through the collection of in-depth accounts of the participants about phenomenon studied. The study used an interview guide with focused interview questions on the implementation of public-private partnerships. The study rationale for interview usage comprised the gathering of descriptive accounts directly from the selected participants own accounts.

The study purposefully selected four participants with extensive experience and knowledge on public infrastructure investment and public private partnerships. There were two participants with Czech origin and two participants with South African origin. Two participants comprised of academic occupations whilst the remaining two participants, one came from the private sector and the last one from the public sector. The study voluntarily requested to participate in this study where a letter explained the purpose of the study was sent and their permission was obtained and flexible interview schedules was obtained. Confidentiality and 
anonymity of participant's responses was guaranteed. The interview took one hour for each participant. The study analyzed collected data through content analysis which adopted grounded theory which was inductive in nature generating concepts that contributed to generation of theory. Atlas.ti was also used to manage, store and help in data retrieval.

\section{Findings and discussion}

The interviews provide interesting results. The first output is the list of most important PPP success factors (Table 1).

\section{Tab. 1 List of the Important Success Factors}

\begin{tabular}{llll}
\hline No & Most Important Success Factors & Range & Rank \\
\hline 1 & Legal and regulatory framework & 22 & 1 \\
2 & Public servant's preparedness & 20 & 1 \\
3 & Technical feasibility studies & 20 & 1 \\
4 & Risk allocation & 19 & 2 \\
5 & Monitoring and evaluation & 15 & 2 \\
6 & Decision making & 14 & 3 \\
7 & Project procurement & 13 & 3 \\
8 & Cost benefit analysis & 12 & 3 \\
9 & Public institutional readiness & 12 & 3 \\
10 & In-house technical expertise & 11 & 3 \\
11 & Risk management & 8 & 4 \\
12 & Good partnerships & 7 & 4 \\
13 & Methodological support & 6 & 4 \\
14 & Clear vision & 6 & 4 \\
15 & Competition & 6 & 4 \\
16 & Land acquisition & 3 & 5 \\
17 & PPP contract management & 3 & 5 \\
18 & Capacity building & 2 & 5 \\
19 & Financing capacity & 2 & 5 \\
20 & Project management & 2 & 5 \\
21 & Governance & 1 & 5 \\
22 & Ownership & 1 & 5 \\
23 & Project benefits & 1 & 5 \\
\hline
\end{tabular}

Source: Own research.

The Table 1 ranked findings into five ascending order of importance. The first level most important success factors include the (1) legal and regulatory framework, (2) public servant's preparedness and (3) technical feasibility studies. Findings suggest that for any success implementation of PPP infrastructure investment projects there has to be a sound or harmonized legal and regulatory 
framework that ensures the success implementation of PPPs. Public servants need to be prepared to implement PPPs and the technical feasibility studies need to be performed to assess the viability of implementing the infrastructure targeted projects. Suhaiza (2013) demonstrates that there is necessity of a well-defined framework and that PPP projects tend to work best with existing and harmonized legal and regulatory framework that is conducive to PPPs.

Risk allocation, monitoring and evaluation are, according to experts, the second level success factors, important to successfully implement PPP infrastructure projects. There is a need to identify risks from the beginning during the technical feasibility studies and to ensure that risks are allocated equally to the best possible partner. Hall (1998) or Ball, Heafey and King (2000), argue that risk allocation is a crucial element in any PPP infrastructure investment project and thus, optimal allocation of risks maximizes the value for money through the PPP project. Projects also have to be continuously monitored and evaluated during the lifecycle of the PPP infrastructure investment project being implemented.

Other important factors are decision making, project management, cost benefit analysis, public institutional readiness and the in-house technical expertise. Aziz et al (2010) indicate that the realistic projections of PPP implementation should base on cost-benefit analysis contributes to methodological support or political will to implement PPP projects. Furthermore, findings suggest a need to understand project procurement and a need for greater in house technical expertise for the realistic implementation of PPP projects.

Tiong and Alum (1997), Gupta and Norasimham (1998) illustrate that the factors which contribute to success implementation of PPP comprise the "strength of the consortia" and "strong and good private consortia" (also Li et al, 2005). Findings also illustrate the need for strong competition. Zhang (2005) also explains that the need for "reliable concessionaire consortium with strong technical strength" is a necessity. Findings also illustrate the need for clear vision, for strong methodological support, good partnership and the effective management of risks. According to Jacobson and Choi (2008), "visionary planning, commitment, open communication and trust, willingness to collaborate and the compromise, political support, risks awareness, clear roles and responsibilities" support and enforce the success rate of PPP implementation.

The opinion of experts ranks other factors but lower, but we have to stress that even factors ranked "5" may have a huge impact into PPP infrastructure investment projects. Tiong and Alum (1997), Gupta and Norasimham (1998) for example indicate that the need for robust understanding of PPP projects by the community is important because the "absence of robust and clear agreement" adversely affect the implementation of PPP infrastructure investment projects due to lack of land acquisition and that capacity building also benefits communities 
from the projects implemented. The lack of ownership adversely affects the whole project management processes and the governance of PPP infrastructural investment projects.

\section{Implications and conclusion}

The study investigated the most important success factors with implementation of PPP infrastructure investment projects with reference to the public sector. Its core results is expert opinion based list and ranking of the success factors of PPPs. We shall stress that despite to the differences in the rankings of the most important success factors in this study, all listed factors may play crucial role in relation to the results of realized PPP projects. This statement is supported by many similar findings, based on the analysis of PPP infrastructure project in several countries, also because the nature and characteristics of PPPs differ across various countries and implementation areas.

The results provide important lesson to the public sector via listing and analyzing of core success factors for PPP implementation. The results shall be understood as the concrete opinion of experts from two countries, combined with the general existing knowledge. Their use shall be connected with the acceptance of the fact that each country experiences and conditions are unique and thus the implementation of PPP infrastructure investment projects requires a tailored practice, adjusted to specific conditions of the country concerned. Although the list of core success factors for PPP implementation is general, the concrete weights of factors for particular countries remain unique and imply that the "one size fits to all" adoption of existing rankings of success factors may not guarantee the best solutions in concrete specific conditions. The authors recommend that further individualized studies, looking deeper into concrete conditions of the implementation of PPP in countries with different conditions are necessary. Despite of this limitation, this study provides important insights for the implementation of PPPs by the public sector by identifying the most important success factors for the implementation of PPP infrastructure investment projects.

\section{References}

Aseidu, D., 2004. Experts Meet to Discuss State of PPP in the Czech Republic. Available from: <http://www.radio.cz/en/section/curraffrs/experts-meet-todiscuss-state-of-ppp-in-the-czech-republic > . [18 May 2016].

Aziz, A., Karthkeyan, D., Chatri, A .K., Shah, S. K., 2010. Public Private Partnerships in India. Lessons from Experiences. Athena Infonomics, Chennai.

Ball, R., Heafey, M., King, D., 2000. Managing and concluding the PFI process for a new high school: Room for Improvement? Public Management Review 2, 159-170. DOI: 10.1080/146166700411210. 
Xhala, N. C. - Nemec, J. - Kajimo-Shakantu, K.: The Breadth of Success and Failure Factors with PPPs Implementation.

Broadbent, J., Laughlin, R. 2003. Public private partnerships: an introduction. Accounting, Auditing \& Accountability Journal 3, 332-341. DOI: 10.1108/09513570310482282.

Della-Crose, R., Gatti, S., 2014. Financing Infrastructure. International Trends. OECD Journal of Financial Market Trends 1, 123-138. DOI: 10.1787/fmt-2014$5 \mathrm{jxvpb} 4 \mathrm{jfrf1}$.

Dewatripont, M., Legros, P., 2009. Public-private partnerships: contract design and risk transfer. In P. Maystadt: Innovative financing of infrastructure - the role of public-private partnerships: Infrastructure, economic growth and the economics of PPPs. European Investment Bank Papers 1, 120-147.

Gupta, M. C., Narasimham, S. V., 1998. Discussion: CSFs in competitive tendering and negotiation model for BOT projects. Journal of Construction Engineering and Management 5, 430-451. DOI: 10.1061/(asce)0733-9364(1998) 124:5(430).

Hall, P. A., 1998. Governing the economy: The politics of state intervention in Britain and France. Oxford University Press, New York.

Hrncir, R., 2009. Delivering Infrastructure Through PPP: PPP Projects in the Czech Republic. The PPP Journal 66, 70-85.

Jacobson, C., Choi, S. O., 2008. Success factors: Public works and public private partnerships (PPPs) in developing countries. The International Journal of Public Sector Management 6, 637-657. DOI: 10.1108/09513550810896514.

Jamali, D., 2004. Success and failures mechanisms of public private partnerships (PPPs) in developing countries. The International Journal of Public Sector Management 5, 414-430. DOI: 10.1108/09513550410546598.

Jefferies, M., Gameson, R., Rowlinson, S., 2002. Critical success factors of the BOOT procurement system: Reflections from the stadium Australia case study. Engineering Construction and Architectural Management 4, 352-361. DOI: 10.1046/j.1365-232x.2002.00249.x.

Kamenickova, L., 2012. Czech Infrastructure and PPP Forum. Avaiable from: $<$ http://www.bids.cz/en/archiv/konference/Czech_Infrastructure_\&_PPP_Forum_2 012/180>. [4 June 2017].

Kovalcik, J., 2010. Transport Ministry Ex-Management Faked Facts about PPPs. Slovak Center. Available from: <http://www.slovenskeecentrum.sk/en/news/read/ 16236/kovalcik-transport-ministry-ex-management-faked-facts-about-ppps>. [25 May 2016].

Kovalcik, J., 2015. The Ministry of PPP Highway Reintroduced. Available from: <http://www.ineko.sk/clanky/ministerstvo-o-ppp-dialnici-opaet-zavadza>. $[24$ May 2016]. 
Kubina, P., 2015. The Future of PPP and Infrastructure Projects in Slovakia. Available from: <http://ceelm.com/index.php/legal-analysis-infrastructure-ppp/ 121-ppp-infrastructure/3679-the-future-of-ppp-and-infrastructure-projects-inslovakia>. [28 June 2016].

Ngowi, A. B., Pienaar, E., Akindele, O., Iwisi, D., 2006. Globalisation of the Construction Industry. A Review of Infrastructure Financing. Journal of Financial Management and Property Finance 1, 45-58. DOI: 10.1108/13664380680001079.

Ondracka, D., 2007. Why Study PPP (Public Private Partnerships) Why Caution? PPP in the Czech Republic: Implementation and Risks. Transparency International Czech Republic, Prague.

Roseneau, P., 1999. The strength and weakness of public private policy partnership. Behavioral Scientist 1,10-34.

Soni, S., 2015. Failure of Public-Private Partnership in India. Economic Policy Forum, Beijing.

Spackman, M., 2002. Public-private partnerships; Lessons from the British approach. Economic Systems 3, 283-301. DOI: 10.1016/s0939-3625(02)00048-1.

Suhaiza, I., 2013. Critical success factors of public private partnership (PPP) implementation in Malaysia. Asia-Pacific Journal of Business Administration 1, 6-19. DOI: $10.1108 / 17574321311304503$.

Tiong, R. L. L., Alum, J., 1997. Evaluation of proposals for BOT projects. International Journal of Project Management 2, 67-72. DOI:10.1016/s026317863(96)00003-8.

Zhang, X., 2005. Critical success factors for public-private partnerships in infrastructure development. Journal of Construction Engineering and Management 1, 3-14. DOI: 10.1061/(asce)0733-9364(2005)131:1(3). 
